\title{
Review \\ Review on the Development and Application of Directional Water Transport Textile Materials
}

\author{
Ya-Qian Xiao and Chi-Wai Kan * (D)
}

Institute of Textiles and Clothing, The Hong Kong Polytechnic University, Hung Hom, Kowloon, Hong Kong 999077, China; yaqian.xiao@polyu.edu.hk

* Correspondence: tccwk@polyu.edu.hk

\begin{abstract}
Moisture (sweat) management in textile products is crucial to regulate human thermo-physiological comfort. Traditional hydrophilic textiles, such as cotton, can absorb sweat, but they retain it, leading to undesired wet adhesion sensation and even excessive cooling. To address such issues, the development of functional textiles with directional water transport (DWT) has garnered great deal of interest. DWT textile materials can realize directional water transport and prevent water penetration in the reverse direction, which is a great application for sweat release in daily life. In this review article, the mechanism of directional water transport is analyzed. Then, three key methods to achieve DWT performance are reviewed, including the design of the fabric structure, surface modification and electrospinning. In addition, the applications of DWT textile materials in functional clothing, electronic textiles, and wound dressing are introduced. Finally, the challenges and future development trends of DWT textile materials in the textile field are discussed.
\end{abstract}

Keywords: functional textiles; directional water transport; asymmetric wettability; wetting gradient; capillary effect

check for

updates

Citation: Xiao, Y.-Q.; Kan, C.-W. Review on the Development and Application of Directional Water Transport Textile Materials. Coatings 2022, 12, 301. https://doi.org/ 10.3390/coatings12030301

Academic Editor: Fabien Salaün

Received: 21 January 2022

Accepted: 16 February 2022

Published: 23 February 2022

Publisher's Note: MDPI stays neutral with regard to jurisdictional claims in published maps and institutional affiliations.

Copyright: (c) 2022 by the authors. Licensee MDPI, Basel, Switzerland. This article is an open access article distributed under the terms and conditions of the Creative Commons Attribution (CC BY) license (https:// creativecommons.org/licenses/by/ $4.0 /)$.

\section{Introduction}

Moisture (sweat) management in textiles has attracted increasing attention because it has great impacts on the physiological comfort of the human body, particularly in the case of sportswear and workwear apparel [1]. In general, textiles with moisture-wicking capability can promote the transportation of liquid sweat and water vapor from the skin to the environment to keep the human body dry and cool. To enhance the moisture-wicking properties of the fabric, most fabrics are composed of synthetic fiber, including polyester, polypropylene, and nylon, due to their excellent wash and wear, anti-wrinkle, and quick-drying properties [2]. Additionally, various methods have been used to improve the moisture-wicking ability of fabrics, such as the use of profiled fibers [3,4], hydrophilic/hydrophobic surface modification [5,6] and hydrophobic and hydrophilic blend/double-layer [7,8]. However, water transport in such fabric is bidirectional, i.e., it can be transported from the skin to the environment as well as from the humid environment to the skin. Therefore, the development of a new functional textile with directional water transfer (DWT) is highly needed to achieve more efficient moisture management.

Directional water motion guided by the synergistic effect of both structure and wettability gradient has been found in nature, such as the desert beetle [9], spider silk [10], cactus [11,12] and nepenthes [13]. Inspired by these natural phenomena, considerable research about the development of DWT textile materials has been reported [14-16]. DWT textile materials fabrics can drive water transfer from skin to outer layer and hinder water transport in the opposite direction. Consequently, DWT textile materials have received much attention and show potential application in many fields, including health $[17,18]$, energy [19] and fog collection [20,21].

Here, we provide a review of the most recent progress on directional water transport textile materials. First, we describe in detail the mechanism of DWT textile materials. Then, 
the preparation methods are summarized, including structural design, surface modification, and electrospinning. In addition, the applications of DWT textile materials are introduced in functional clothing, electronic textiles, and wound dressing. Finally, the challenges and prospects of DWT textile materials are highlighted.

\section{Mechanism of Directional Water Transport}

\subsection{Wettability Theory}

Generally speaking, the wetting behavior of a fabric surface has a deep influence on water transportation. When a droplet of liquid is placed on a smooth solid surface, the wettability of the surface can be calculated using Young's equation (Equation (1)) (Figure 1a) [22]:

$$
\cos \theta=\frac{\gamma_{S V}-\gamma_{S L}}{\gamma_{L V}}
$$

where $\gamma_{S V}, \gamma_{S L}, \gamma_{L V}$ are the interfacial tension of the solid-vapor, the solid-liquid, and the liquid-vapor, respectively, and $\theta$ is the equilibrium contact angle. The equation has been widely used to explain wetting and wicking phenomena. Young's equation is only applicable to smooth and homogeneous surfaces, while most substrate surfaces have roughness. Additionally, surface roughness is related to the wettability of the material. Therefore, Wentzel state and Cassi state were proposed to illustrate the liquid contact angles for rough surfaces. The liquid droplet may penetrate pores of rough surface (i.e., Wenzel state), as shown in Figure 1b. The surface roughness's impact on contact angle can be calculated by Equation (2) as [23]:

$$
\cos \theta_{m}=r \cos \theta
$$

where $r$ is the surface roughness ratio and $\theta$ is Young's contact angle. $\theta_{m}$ is the measured contact angles of the rough surface. In the Cassi state, due to the air entrapped in the solid-liquid interface, the liquid cannot penetrate the pores of the rough surface (Figure 1c). The contact angle can be described by Equation (3) [24]:

$$
\cos \theta_{m}=f_{S L} \cos \theta+1-1
$$

where $f_{S L}$ is the area fraction of the liquid droplet in contact with the solid surface.

(a)

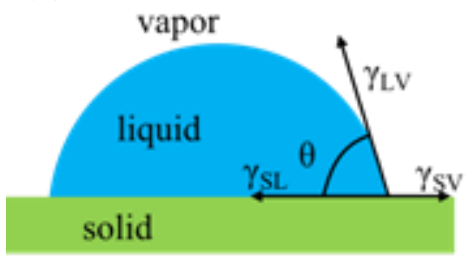

(b)

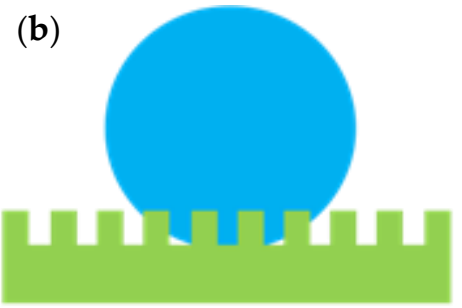

(c)

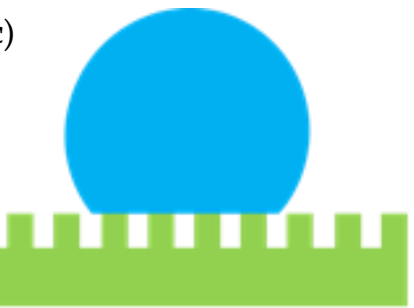

Figure 1. Different wetting behaviors of the solid surface: (a) Young state; (b) Wenzel state; and (c) Cassie state.

\subsection{Transporting Theory}

When a liquid in a capillary wets the walls of the capillary, a meniscus is formed. The surface tension of the liquid causes a Laplace pressure $\left(P_{L}\right)$ across the curved liquid-air (vapor) interface, related to the curvature of this interface (Equation (4)):

$$
P_{L}=\frac{2 \gamma \cdot \cos \theta}{r}
$$

where $\gamma$ is the surface tension of liquid water, $\theta$ is the advancing water contact angle (WCA) of the inner surface of the capillary, and $r$ is the pore radius. 
When the liquid comes into contact with the material surface, it enters the internal fiber channel and is dragged by Laplace pressure. It is worth noting that both $\theta$ and $r$ are significant parameters affecting the capillary rise, where $\theta$ is responsible for determining the direction of water movement driven by the Laplace pressure and $r$ is inversely proportional to the Laplace pressure. Consequently, a fabric with unidirectional water transport can be reached by designing different pore structures and wettability of each layer. Many materials, including woven fabric, nonwoven and electrospinning nanofibers, have realized directional water transfer [25-27]. According to the wettability profile, these porous materials can be categorized into two major types: Janus wettability and wettability gradient [28]. Janus wettability relies mainly on the asymmetric water absorption properties of the inner and outer layers of textile materials to accelerate the rate of water transportation. The wettability gradient relies on micro-pores in the material to guide directional water transport. Recently, many interpretations have been proposed to unravel the water transport process.

For instance, Yan et al. [29] demonstrated a possible mechanism for directional water transfer by a hydrophobic/superhydrophilic Janus membrane (Figure 2a). When the water was dropped on the hydrophobic layer of the Janus membrane, it was affected by two opposite forces, i.e., hydrostatic pressure $(\mathrm{HP})$ and hydrophobic force $\left(\mathrm{F}_{\mathrm{Ho}}\right)$. HP was related to the size of the droplet, while the $\mathrm{F}_{\mathrm{HO}}$ depends on the surface structure and surface chemical composition of the hydrophobic layer. Once the HP is larger than the $\mathrm{F}_{\mathrm{Ho}}$, water penetrates through the hydrophobic layer. Then, the capillary force $\left(\mathrm{F}_{\mathrm{C}}\right)$ of the superhydrophilic layer pulls the water off the hydrophobic layer and spreads it throughout the superhydrophilic layer. On the contrary, when water is dropped on the superhydrophilic layer, Fc immediately captures the water and disperses it in the superhydrophilic layer and also reduces the hydrostatic pressure. Furthermore, the $\mathrm{F}_{\mathrm{HO}}$ of the hydrophobic layer and asymmetric wettability of the two layers of the composite membrane prevent the further penetration of water.

(a) (i)

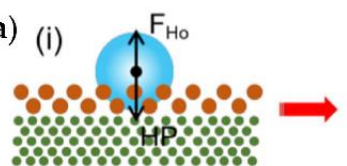

(ii)

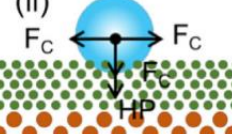

PAN

HP: Hydrostatic pressure $F_{\mathrm{Ho}_{0}}$ : Hydrophobic force $F_{\mathrm{C}}$ : Capillary force

(b)

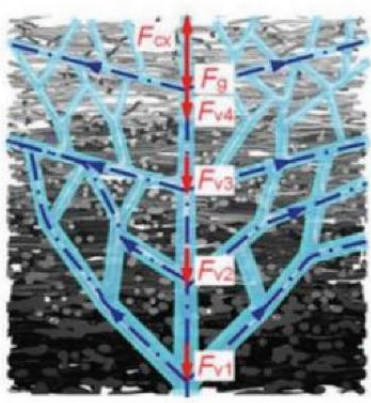

(c)
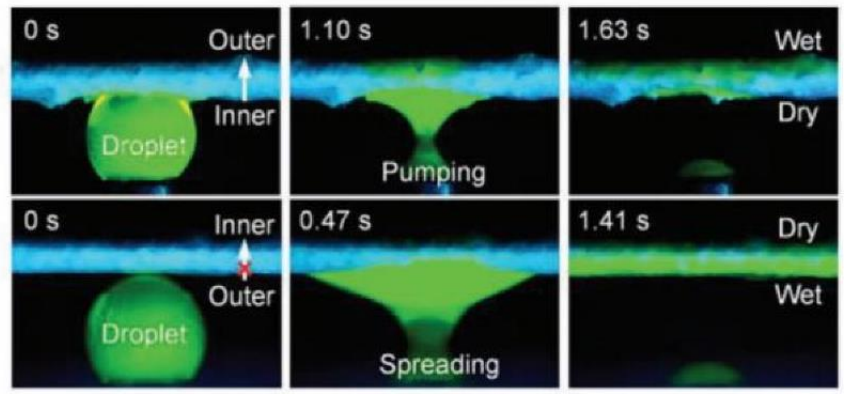

Figure 2. (a) The possible mechanism for directional water transfer by a hydrophobic/superhydrophilic Janus membrane [29] (Copyright 2020, Elsevier Inc.). (b) Illustration of the spontaneous vertical wicking in the multilayer membrane. (c) Fluorescence images of the antigravity water transport in the multilayers [30] (Copyright 2021, Wiley-VCH). 
Miao et al. [30] designed a four-layered fibrous material with decreasing fiber diameters and demonstrated the directional water transport mechanism of the multilayer membrane with a hierarchical fibrous structure (Figure $2 b$ ). When water was dropped on the bottom layer, it was mainly affected by three forces: capillary force $\left(\mathrm{F}_{\mathrm{c}}\right)$; viscous resistance $\left(\mathrm{F}_{\mathrm{v}}\right)$; and self-gravity $\left(\mathrm{F}_{\mathrm{g}}\right)$. The water was spontaneously pumped into the fibrous membranes because the $F_{c}$ was greater than the $F_{v}$ and $F_{g}$. Therefore, water was pumped upward from the first layer to the second layer under the capillary pressure difference $(\Delta P)$, as in Equation (5):

$$
\Delta P=P_{L X+1}-P_{L X}=\frac{2 \gamma \cdot \cos \theta}{r_{X+1}}-\frac{2 \gamma \cdot \cos \theta}{r_{X}}
$$

where $r_{X+1}$ and $r_{X}$ are the radii of pores of the first and the second layer, respectively.

Considering that the $P_{L X+1}$ was larger than $P_{L X}$ in this biomimetic multilayer fibrous membrane, $\Delta P$ played a key role in continuously pumping the water upward. When a finite amount of water was transported into the porous media with multi-scale pores, it tended to be redistributed from larger pores into smaller ones. In addition, for the vertical capillary rise in the multilayers, the total capillary force was determined by the last layer where water was finally pumped, while the total viscous resistance (i.e., the effect of surface friction between a particle and a liquid when the particle moves through the liquid) was equal to the sum of each layer. Therefore, the multilayer membrane with a hierarchical fibrous structure possessed the maximum capillary force and relatively lower viscous resistance, maximizing the directional water transport. As shown in Figure 2c, when water touched the inner layer, it could quickly pass from the inner to the outer layer. On the contrary, when the outer layer was down, water just spread horizontally without penetration.

\section{Method for Preparation of Directional Water Transfer Textile Materials}

\subsection{Structural Design}

Structural design refers to the structure of the fabric, i.e., knit fabric, woven fabric, and nonwoven, with various proportions of hydrophobic/hydrophilic fibers for preparing DWT fabric. DWT fabrics with structural design do not use chemical reagents, which can directly come into contact with the human skin and provide stable directional water transfer performance. Many studies have reported that asymmetric wettability could be achieved by adjusting the thickness of the hydrophilic or hydrophobic layer of the fabric [31-33].

Based on this method, Song et al. [34] constructed the gradient wettability nonwoven by hydroentanglement which consisted of hydrophobic chitosan (CS) fibers and hydrophilic viscose (VIS) fibers (Figure 3a). The gradient wettability allowed water penetration from the hydrophobic layer to the hydrophilic layer without penetration from the opposite direction (Figure $3 \mathrm{~b}$ ). It should be pointed out that, even when $90 \%$ of the fibers are hydrophobic and the hydrophobic layer exceeds a record-high thickness of $1.6 \mathrm{~mm}$, a composite nonwoven material still could reach anisotropic water penetration. In addition, a composite fabric could maintain a good abrasion resistance and anisotropic water penetration after 300 cycles of abrasion. Significantly, the composite nonwoven is environmentally friendly and can be mass produced, and it has uses in healthcare applications.

In another study, Zhen et al. [27] developed a polylactic acid (PLA)-VIS composite fabric with a wettability gradient structure by combining needle punching and through-air bonding (Figure 3c). Wettability gradient structures were obtained by laminating five-layer cross-laid fibrous webs with various mass ratios of VIS fiber distributions along the thickness direction, and fluffy structures with porosities ranging from 90 to $96 \%$ were obtained using a porous frame in an oven. Thus, the one-way transport index (AOTI) values increased from 77.8 to $165.6 \%$ as the wettability gradient index $\left(R_{v}\right)$ values increased from 0 to 1.5 . 
(a)

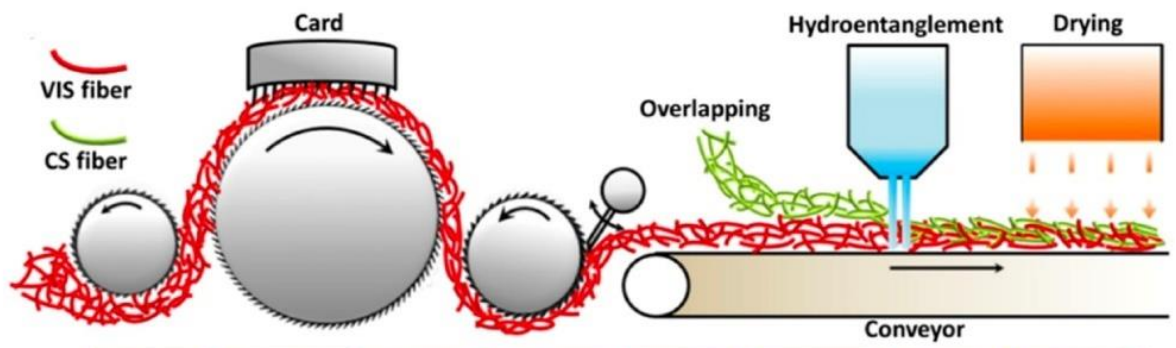

(b)
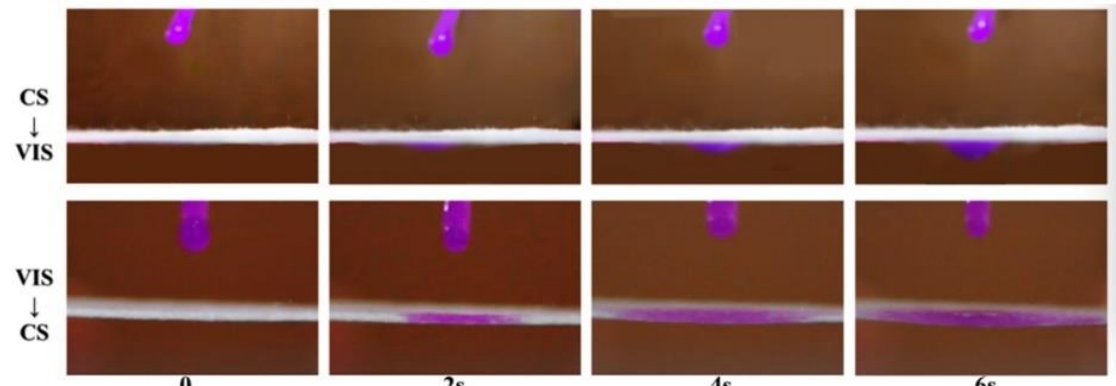

(c)
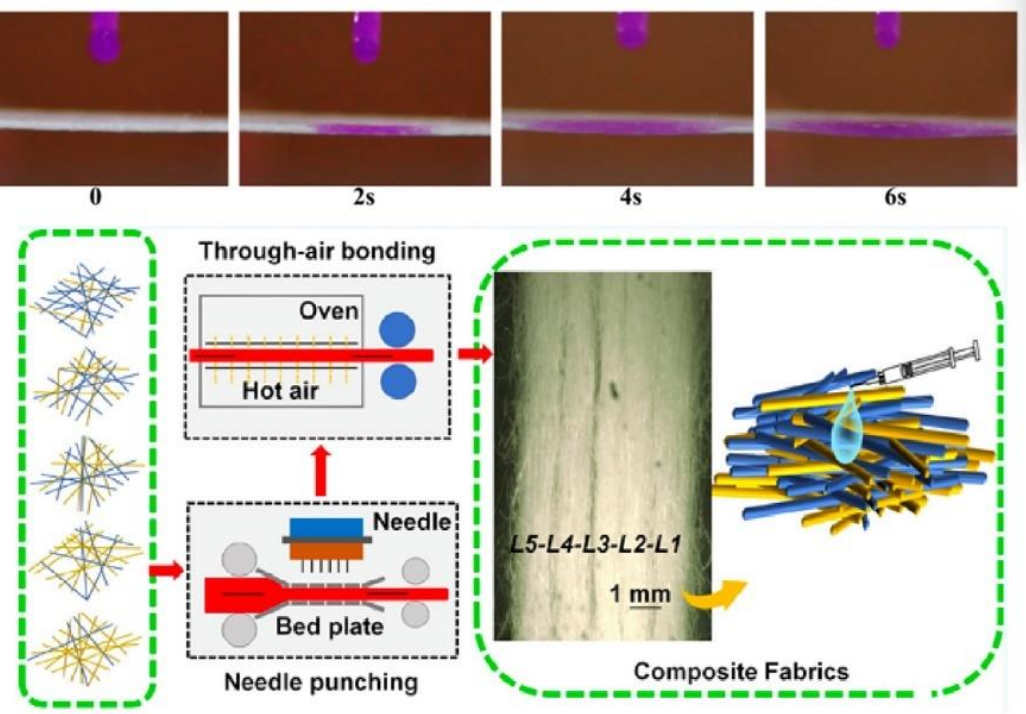

Figure 3. (a) Schematic illustration of the fabrication of the CS/VIS composite nonwoven fabric; (b) water-penetration phenomenon from both sides of the composite [34] (Copyright 2019, American Chemical Society). (c) Schematic illustration of the fabrication of composite fabrics via the combination of needle punching and through-air bonding process [27] (Copyright 2021, American Chemical Society).

\subsection{Surface Modification}

\subsubsection{Plasma Treatment}

As a newly developing technology, plasma treatment has been used to modify wettability of fabric without changing the internal composition of the fiber. Many types of Janus fabrics have been fabricated by using plasma treatment for depositing low surface energy materials on hydrophilic fabric, mainly including polymerized hexamethyldisilane (HMDSO) and fluoropolymer (poly $(3,3,4,4,5,5,6,6,7,7,8,8,9,9,10,10,10$-heptadecafluorodecyl methacrylate, PHFDMA) [35,36].

Lao et al. [37] fabricated a "skin-like" fabric by creating gradient wettability channels across a hydrophobic substrate. As shown in Figure 4a, a superhydrophobic fabric was prepared by coating $1 \mathrm{H}, 1 \mathrm{H}, 2 \mathrm{H}, 2 \mathrm{H}$-perfluorooctyltriethoxysilane (PFOTES)/titanium dioxide $\left(\mathrm{TiO}_{2}\right)$ nanoparticles onto a cotton fabric, followed by one side selective plasma treatment with a patterned mask to create porous hydrophilicity channels. The gradient wettability channels across superhydrophobic substrate were employed to endow fabric with directional water transfer and water repellency (Figure $4 \mathrm{~b}$ ). It should be mentioned that the permeability, mechanical property, and abrasion resistance (up to 10,000 cycles) of the fabric were not affected by superhydrophobic finishing and plasma treatment. Recently, $\mathrm{Pu}$ et al. [38] prepared a Janus fabric via plasma depositing HMDSO on the surface of cotton nonwoven fabric. The treated fabric surface showed superhydrophobicity with a contact angle (CA) of $150^{\circ}$ due to the HMDSO low-surface-energy material, and the untreated 
fabric surface showed hydrophilicity with CA of $0^{\circ}$. This asymmetric wettability enabled the nonwovens to exhibit directional water transport performance, good water-vapor transmission rate (MVTR) of $0.19 \mathrm{~kg} \mathrm{~m}^{-2} \mathrm{~d}^{-1}$, and high air permeability of $1208 \mathrm{~mm} / \mathrm{s}$.

(a)

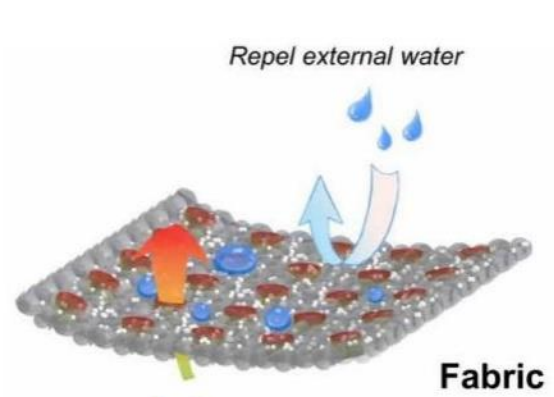

(b)

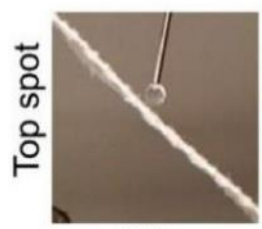

Directional water flow
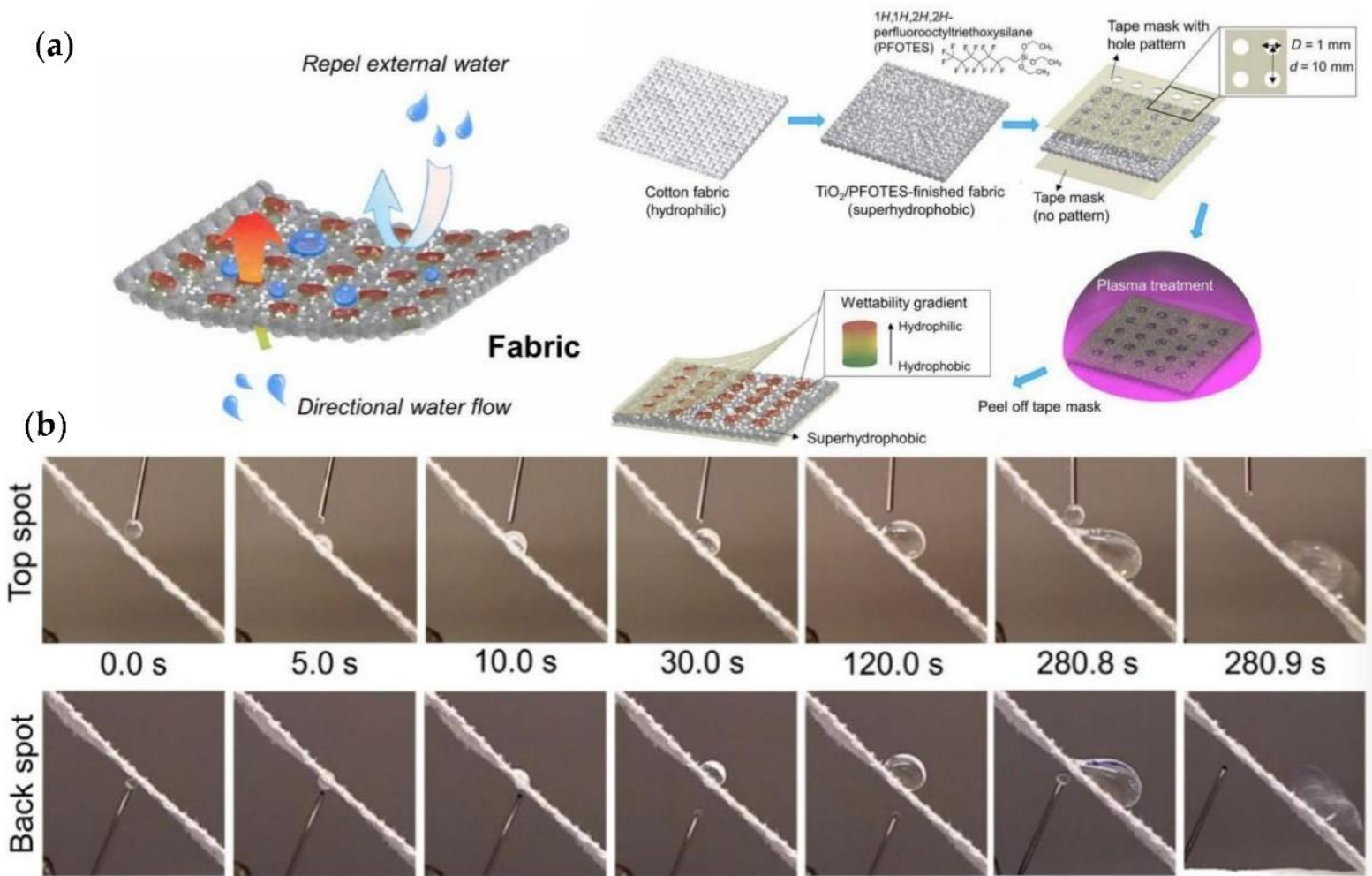

$120.0 \mathrm{~s}$

$280.8 \mathrm{~s}$

$280.9 \mathrm{~s}$

$0.0 \mathrm{~s}$

$5.0 \mathrm{~s}$

$10.0 \mathrm{~s}$

$30.0 \mathrm{~s}$

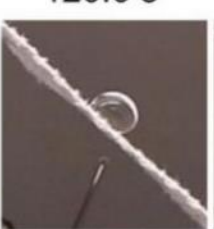

$120.0 \mathrm{~s}$

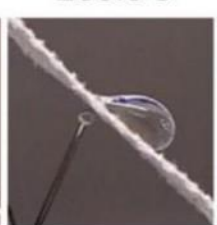

$248.5 \mathrm{~s}$

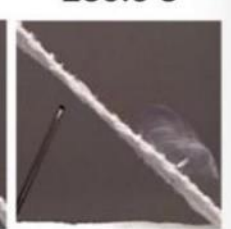

$249.0 \mathrm{~s}$

Figure 4. (a) Schematic illustration for the fabrication of a "skin-like" fabric with on-way water transfer and water repellency. (b) Water drops on the top side of the fabric (hydrophilic) and rolls off from the fabric without penetrating; water drops on the back spot (hydrophobic) and spontaneously are transported from the backside to the other side, and then roll off from the top surface [37] (Copyright 2020, Science Advance).

\subsubsection{Electrospraying Coating}

Electrospraying involves very fine liquid droplets from bulk liquid at a high electric potential [39]. As the charges and size of droplets can be controlled by changing the voltage and flow rate, electrospraying can control coating thickness, and thus adjust the thickness of the hydrophobic layer, which is important for the UWT performance of fabrics. To date, many DWT fabrics have been fabricated through electrospray coating of low surface energy materials on the hydrophilic fabric, including fluoropolymers and siloxanes [25,40].

Recently, Wang et al. [41] prepared a DWT fabric by a two-step electrospray method, in which a superhydrophobic pattern fabric was fabricated via the electrospray coating of perfluoroalkyl acrylate onto cotton fabric, followed by one-side electrospray treatment (Figure 5a). In comparison with the non-patterned directional water transport fabric, the one with superhydrophobic patterns had 1.89 times higher accumulative one-way transport capacity index with high air permeability.

In another study, Wang et al. [42] fabricated one-way water transfer fabrics by electrospraying a thin layer of hydrophobic PVDF-HFP/FAS on a hydrophilic cotton fabric (Figure $5 b, c)$. The fabric exhibited one-way water transfer performance when the hydrophobic layer thickness was between $9.0 \mu \mathrm{m}$ and $23.9 \mu \mathrm{m}$. This proved that the pore size of the hydrophilic layer has a critical effect on DWT performance and smaller pores show larger DWT capacity. In another study, a more environmentally friendly DWT fabric without low-surface-energy materials, such as fluorine or silicon fluorine, was prepared 
by electrospray depositing hydrophobic polymers on cotton and synthetic fabrics [43] Electrospraying of polymers forms a rough layer on the fabric surface and generates a roughness gradient structure along with the fabric thickness. The fabrics were found to be endowed with high one-way water transfer property, as well as good air permeability of $33.6 \mathrm{~cm}^{3} \mathrm{~cm}^{-2} \mathrm{~s}^{-1}$ (Figure $5 \mathrm{~d}, \mathrm{e}$ ).

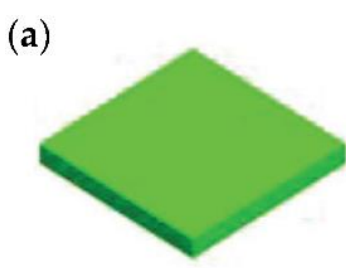

Superhydrophilic fabric

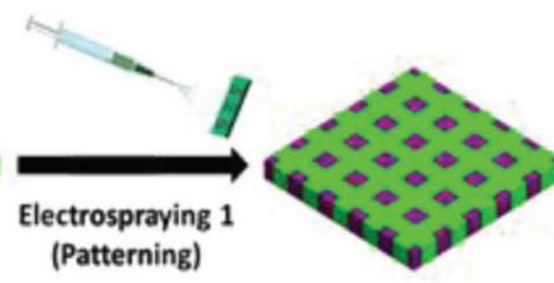

Superhydrophobic coating

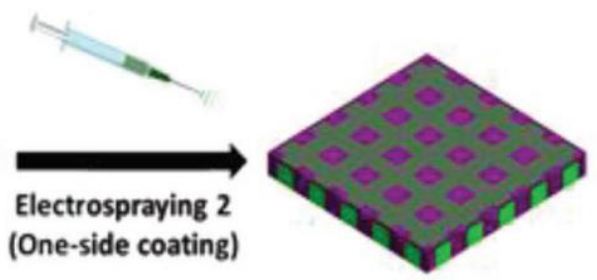

(One-side coating)

Patterned and one-side coating
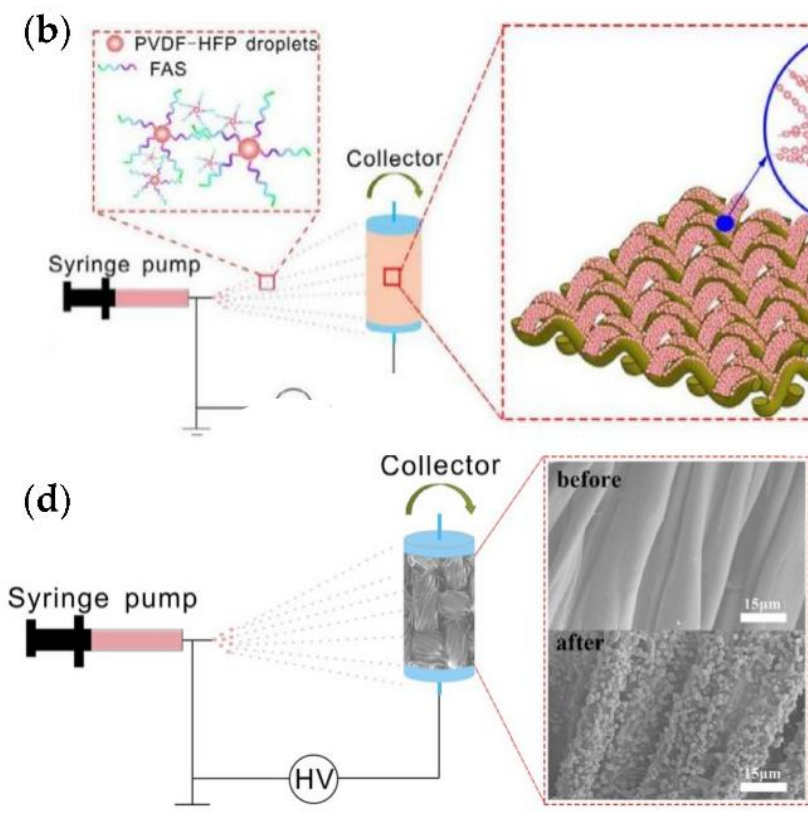

(c)

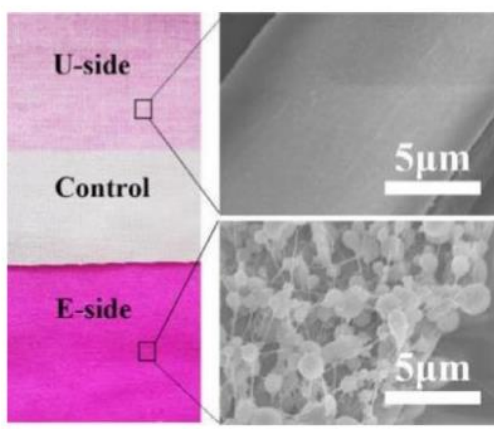

(d)

\section{Collector}
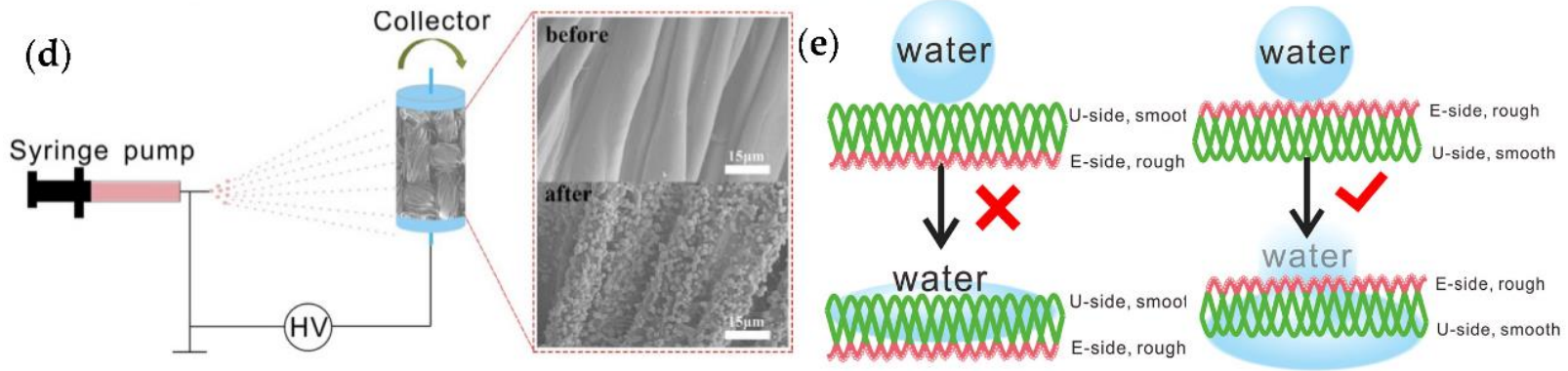

Figure 5. (a) Schematic illustration for the fabrication of a DWT fabric by the two-step electrospray treatment with patterning [41] (Copyright 2018, Wiley-VCH). (b) Schematic illustration for the preparation of UWT fabric by electrospraying coating. (c) Photos of the fabric before and after one-side electrospraying treatment (a pink dye was added into the coating solution to indicate the electrospray layer) and SEM images of the sprayed and un-sprayed fabric sides [42] (Copyright 2018, Elsevier B.V.). (d) Schematic illustration for the fabrication of an environmentally friendly DWT fabric and SEM images of the cotton fabric before and after electrospray polyethylene terephthalate (PET). (e) Illustration of the water transport process when water was dropped on the electrospray and un-electrosprayed fabric sides [43] (Copyright 2018, American Chemical Society).

\subsubsection{Laser Processing}

As a new technology, laser processing has attracted abundant attention in surface micronano fabrication because it is precise, flexible, quick and environmentally friendly [44-46]. A material chemical composition and surface micro/nanostructure affect surface wettability. Therefore, laser processing has been widely applied to prepare various surface wettability properties, including superhydrophobic, superhydrophilic, and superamphiphobic [47-49]. Recently, many researchers have fabricated wettability gradient surface fabric to reach directional water transfer through the laser method with low-energy-surface modification $[50,51]$. 
For instance, inspired by the directional water transport in birds' beak, Dai et al. [52] fabricated a hydrophobic/superhydrophilic Janus polyester (PE)/nitrocellulose (NC) textile material with asymmetric conical micropores arrays for directional sweat liquid transport by laser perforation and subsequent plasma modification (Figure 6a-e). Excessive sweat can be efficiently transferred from the inner layer to the outer layer through asymmetric conical micropores driven by capillary force to keep the skin dry and cool (Figure 6f). The PE/NC textile showed a high directional liquid transport capability (AOTC) of 1246\% and maintained human body temperature. In another study, Yang et al. [53] fabricated a hydrophilic/hydrophobic Janus fabric using a one-step femtosecond laser method. The laser treated surface exhibited micro/nanostructures and hydrophilicity (Figure 6g). The Janus fabric quickly removed extra sweat from the hydrophobic layer to the hydrophilic layer and exhibited a cooling function of $2{ }^{\circ} \mathrm{C}$ lower than traditional fabrics, as shown in Figure $6 \mathrm{~h}-\mathrm{k}$.

(a)

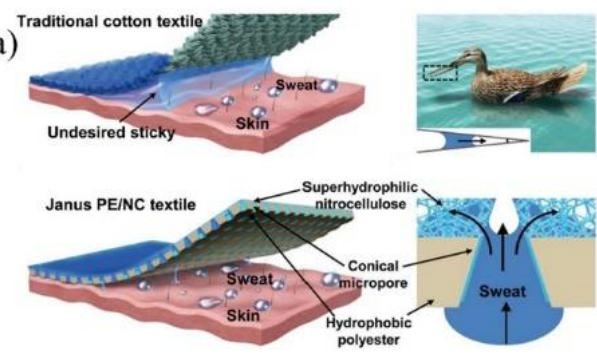

(b)
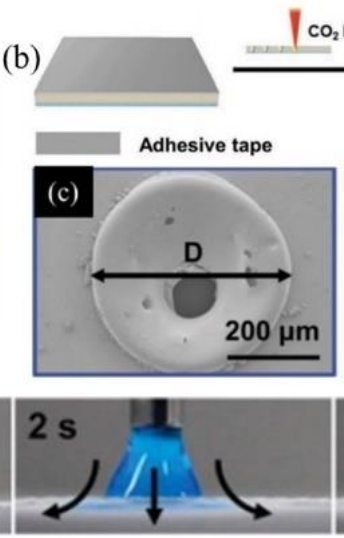

$\underset{\text { Removing tape }}{\stackrel{\text { Plasma modification }}{\longrightarrow}}$

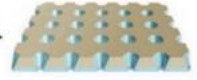
Nitrocellulose layer
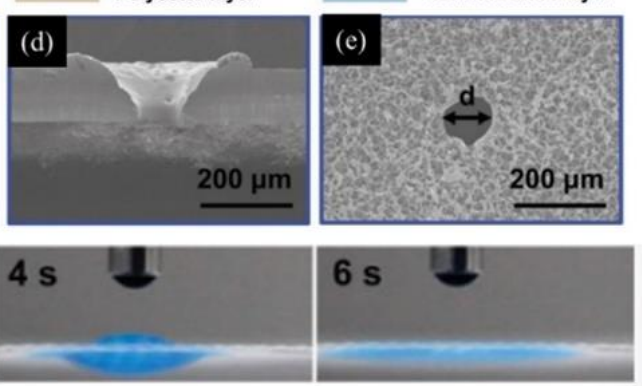
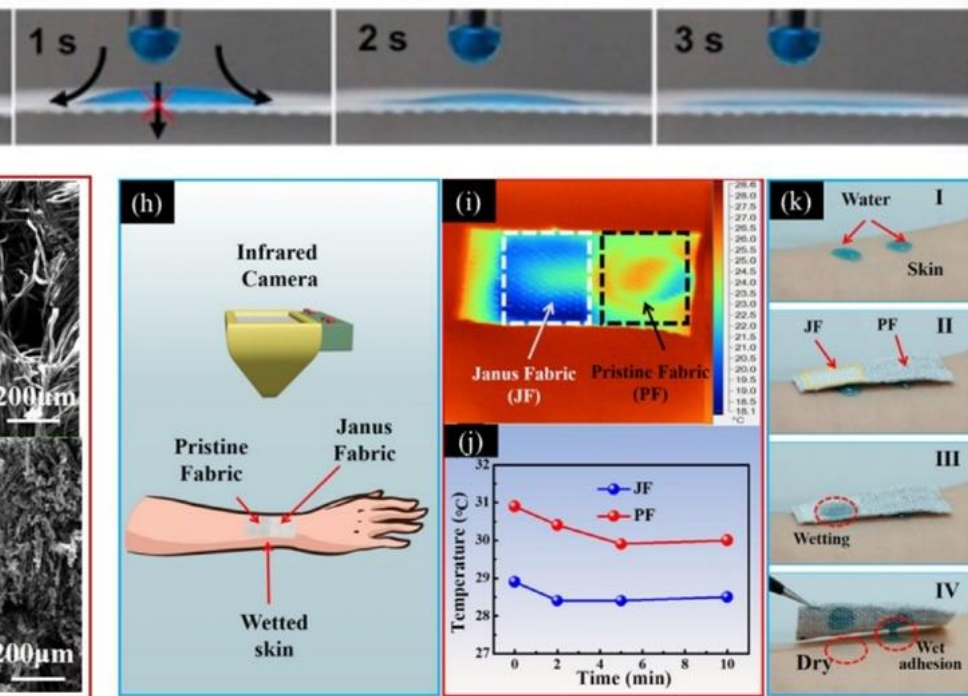

Figure 6. (a) Schematic comparison between sweat transport on skin by a traditional cotton textile and the Janus PE/NC textile that consists of conical micropores for efficient sweat liquid transport directionally. (b) Fabrication of the Janus PE/NC textile. (c-e) SEM images of the PE layer, crosssection, and NC layer of the Janus PE/NC textile. (f) Water drops onto the hydrophobic PE layer and penetrates it immediately; water drops onto the super-hydrophilic NC layer and spreads across its surface [52] (Copyright 2019, Wiley-VCH). (g) Fabrication of Janus fabric process, the water contact angle of the sample surfaces, an optical image of a water droplet on pristine fabric and Janus fabric, and SEM images of pristine fabric and laser-treated fabric. $(\mathbf{h}-\mathbf{j})$ The measured temperature of pristine fabric and Janus fabric on wetted skin. (k) Optical images of the quick liquid transport performance of the Janus fabric [53] (Copyright 2021, Applied Physics Letters). 


\subsection{Electrospinning}

The electrospinning technique is a simple method that uses high electrostatic forces to fabricate nanofibrous membranes [54]. Electrospinning has become an effective approach to construct asymmetric wettability in fibers to prepare DWT fibers, which can control pore size, thickness and wettability of each layer [55-57].

Babar et al. [58] fabricated DWT membranes by electrospinning, which consisted of commercial polyethylene terephthalate nonwoven (CNW) as a hydrophobic layer and polyamide-silver (PA-Ag) nanoparticle nanofiber as hydrophilic layer by one-step electrospinning (Figure 7a,b). The introduction of Ag nanoparticles not only created a combined inter-connected network of nanonets and nanofibers, but also enhanced the wettability of PA. The obtained CNW/PA-Ag membranes with differential pore sizes and decent wettability gradients exhibited excellent AOTC of $1253 \%$, high overall moisture management capability (OMMC) of 0.91 , and good WVTR of $11.45 \mathrm{~kg} \mathrm{~m}^{-2} \mathrm{~d}^{-1}$.

(a)

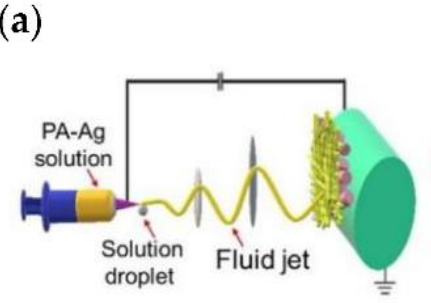

One-step electrospinning

(c) $\mathrm{pu}$
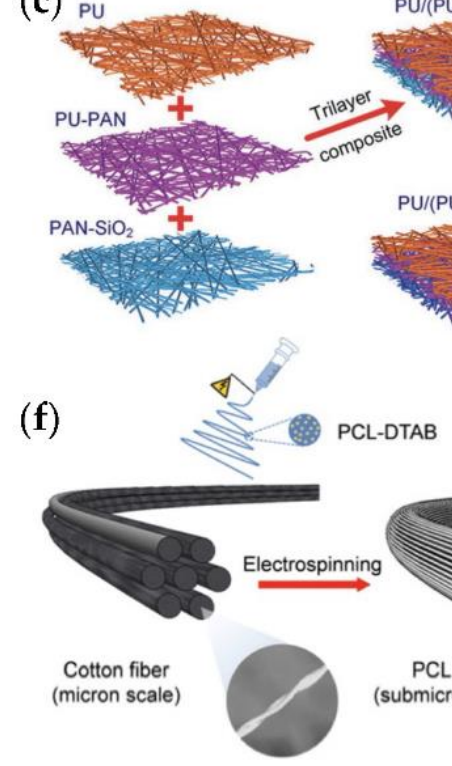
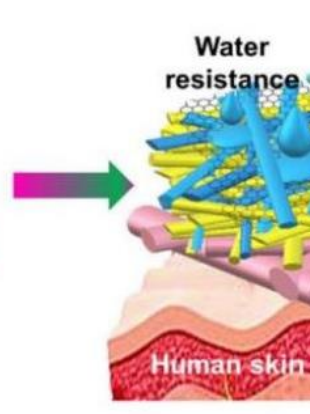

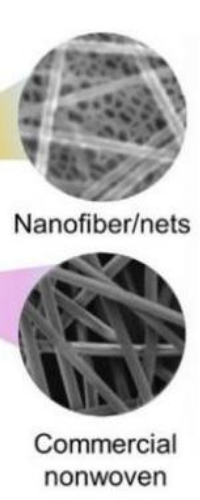
nonwoven (b)

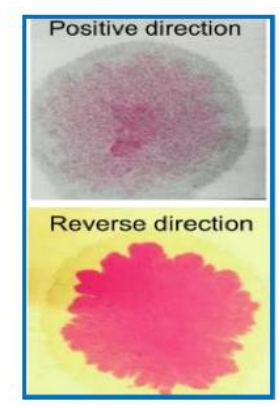

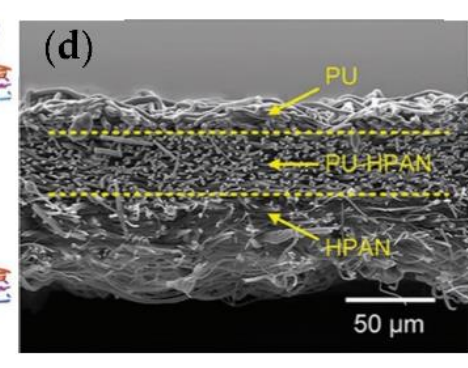

(e)
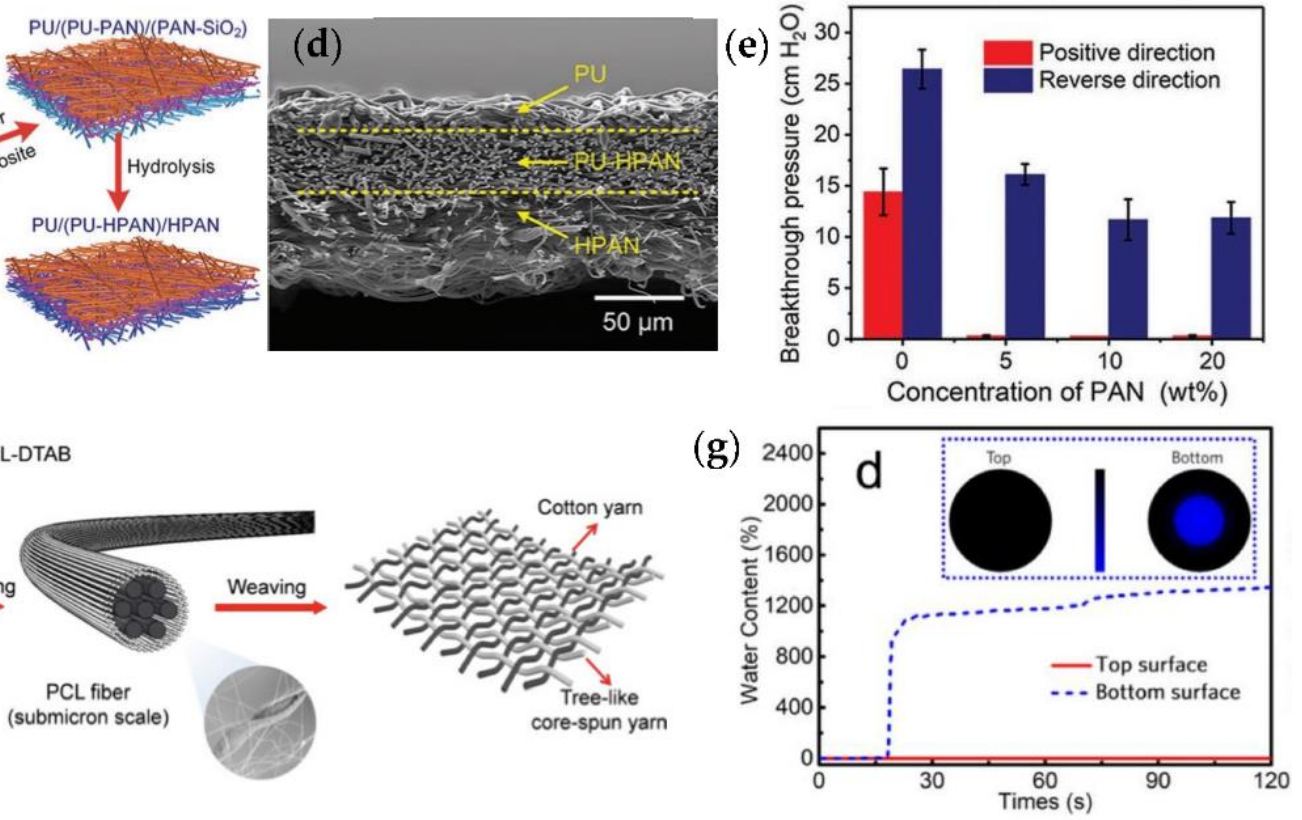

Figure 7. (a) Schematic illustration of the fabrication process of the composite CNW/PA-Ag nanofiber-net membrane. (b) Water drops onto the hydrophobic CNW side and penetrates the membrane. (c) Structure of trilayered PU/(PU-HPAN)/HPAN fibrous membrane [58] (Copyright 2021, Elsevier Inc.). (d) Cross-sectional SEM image of trilayered fibrous membrane. (e) Anisotropic breakthrough pressure of the trilayered fibrous membranes [59] (Copyright 2018, Wiley-VCH). (f) Process of electrospinning to prepare tree-like core-spun yarns and fabrics. (g) MMT results for tree-like core-spun yarn-based fabrics [60] (Copyright 2019, American Chemical Society).

Miao et al. [59] prepared trilayered DWT membranes with superhydrophilic hydrolyzed PAN-SO 2 (HPAN) nanofibers as an outer layer, hydrolyzed PU-PAN nanofibers 
as a transfer layer, and hydrophobic PU nanofibers as inner layer via electrospinning and alkaline treatment (Figure 7c,d). In this study, the hydrophilicity of the PAN and PU-PAN transfer layers could be varied via alkali treatment. It should be mentioned that the transfer layer endowed nanofibers with a wettability gradient, thus guiding the water penetrating from the skin to the outer layer and preventing penetration in the reverse direction. The resultant membrane demonstrated the desired breakthrough pressure of $16.1 \mathrm{~cm} \mathrm{H}_{2} \mathrm{O}$ in the reverse direction and a high one-way transport index $\mathrm{R}$ of $1021 \%$ (Figure $7 \mathrm{e}$ ). The use of alkali treatment to improve the surface wettability by cellulose acetate PU/PAN-PVP [29], (CA)/PAN-PVDF [60] and PVA/PET/PS [61] has also been reported.

Recently, inspired by the water transfer behavior in trees, Mao et al. [62] prepared a tree-like structure of core-spun yarn that consisted of cotton fiber as the core and electrospun polycaprolactone (PCL) nanofibers as a sheath layer using electrospinning (Figure 7f). In this core-spun yarn system, a differential capillary pressure produced by the difference of fiber scale could achieve rapid water transfer between the cotton fiber and electrospun nanofibers. Thus, the fabrics from these fibers showed a high AOTC of $1034.5 \%$ and a good OMMC of 0.88 (Figure $7 \mathrm{~g}$ ).

\section{Applications in the Textile Field}

\subsection{Functional Clothing}

DWT fabrics can spontaneously transport sweat from the skin to the environment and prevent sweat penetration in the reverse direction, thus providing a dry and comfortable microclimate to the human body. To date, DWT fabrics have been widely applied in sportswear and air-condition clothing. Through years of continuous efforts, many different kinds of DWT textile materials have been fabricated for functional clothing, as summarized in Table 1.

Table 1. Summary of DWT textiles for functional clothing.

\begin{tabular}{ccccc}
\hline Material & Method & $\begin{array}{c}\text { AOTC } \\
(\%)\end{array}$ & OMMC & Ref. \\
\hline Cotton fabric & Coating & 860 & - & {$[40]$} \\
Polyester & Laser treated & 966 & 0.92 & {$[63]$} \\
PE/NC textile & & 1246 & - & {$[52]$} \\
NW (TNW)/PAN-SiO 2 & & 919 & 0.99 & {$[64]$} \\
CA/DCA & & 1021 & 0.89 & {$[65]$} \\
PU/(PU-HPAN)/HPAN & & 1034 & - & {$[59]$} \\
core-spun yarn-based fabric & Electrospinning & 1245 & 0.88 & {$[62]$} \\
Murray membranes & & 1253 & 0.94 & {$[66]$} \\
CNW /PA-Ag membranes & & 1311 & 0.91 & {$[58]$} \\
PU /HPPAN & & 1483 & - & {$[29]$} \\
TPU-PVA/HACC & & & - & {$[18]$} \\
\hline
\end{tabular}

Among these, Wang et al. [66] created a biomimetic trilayered fibrous membrane with antigravity directional water transport and quick-dry performance by a combination of multibranch porous structure and surface energy gradient (Figure 8a). It was pointed out that each layer of the trilayered fibrous membrane became finer along the thickness direction, and at the same time, the wettability of these layers became stronger. Thus, the inner pressure gradient could quickly drive water from the skin layer to the outer layer (Figure $8 b$ ). The obtained Murray membrane exhibited excellent AOTC of $1245 \%$ and high $\mathrm{OMMC}$ of 0.94 and outstanding water evaporation rate of $0.67 \mathrm{~g} \mathrm{~h}^{-1}$, which were superior to those of conventional fabrics. 
(a)

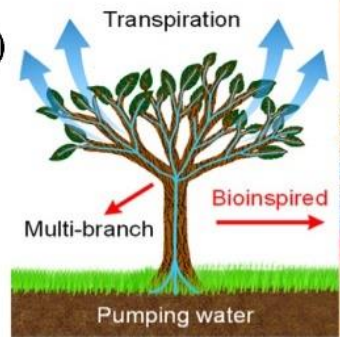

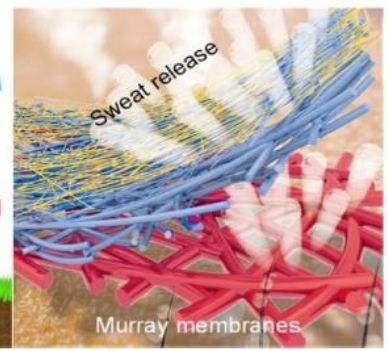

(d)

(c)

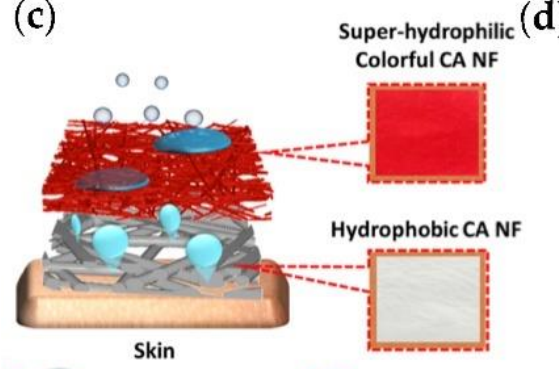

Sweat droplet (b)

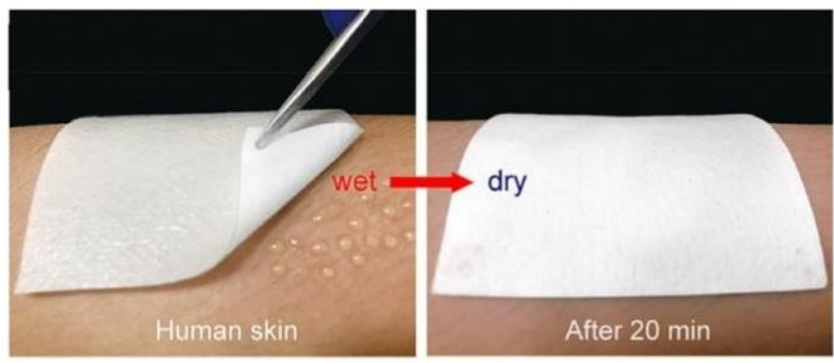

(e)

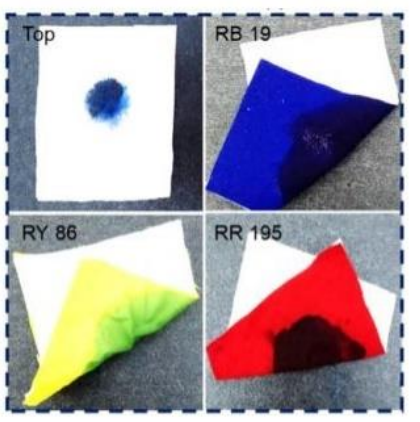

Figure 8. (a) The antigravity directional water transport and schematic demonstration of the sweatrelease process of biomimetic porous Murray membrane. (b) Optical images of the quick-dry performance of the porous Murray membrane [66] (Copyright 2019, American Chemical Society). (c) Schematic illustrating the sweat-release process of the colorful DWT membrane. (d) Optical images of dyed nanofibers after dyeing. (e) Optical images of the water-penetration phenomenon from both sides of the composite membrane [65] (Copyright 2018, American Chemical Society).

Moreover, a colorful DWT membrane has been prepared by combining cellulose acetate (CA) and hydrolyzed and dyed CA (DCA) nanofibers (Figure 8c-e) [65]. By hydrolyzing and dyeing, the DCA layer acquires the superhydrophilic property and can be uniformly colored with a high color yield ( 16.33) and dye fixation $(\sim 82 \%)$. In addition, due to the high gradient wettability of hydrophobic-superhydrophilic layers, the resultant membrane exhibits excellent AOTC of 919\%, remarkable OMMC of 0.89 and good WVT rate of $12.11 \mathrm{~kg} \mathrm{~m}^{-2} \mathrm{~d}^{-1}$.

\subsection{Electronic Textiles}

DWT fabrics with asymmetric wettability can be used as humidity sensors. These can also unidirectionally remove moisture, prevent water droplet penetration, and keep skin dry, which can ensure wear comfort and protect electronic textiles from water intrusion. Therefore, DWT fabrics have attracted increasing attention in electronic textiles [67-69].

He et al. [70] prepared a wearable sweat sensor by integrating Janus textiles and electrode array for detection of multiple physiological biomarkers (Figure 9a). The Janus textile was established through electrospinning a hydrophobic PU nanofiber array onto a superhydrophilic gauze, which could unidirectionally transport sweat from the skin to the electrode surface and guarantee a comfortable microenvironment for the skin. As a result, the sweat sensor could sensitively detect physically relevant sweat composition, including glucose (40 to $18 \mu \mathrm{M}$ ), lactate (around $10 \mathrm{mM}$ ), $\mathrm{K}+$ (from 6.3 to $0.3 \mathrm{mM}$ ), and $\mathrm{Na}+$ (about $60 \mathrm{mM}$ ) in an on-body trial (Figure $9 \mathrm{~b}, \mathrm{c}$ ). 
(a)

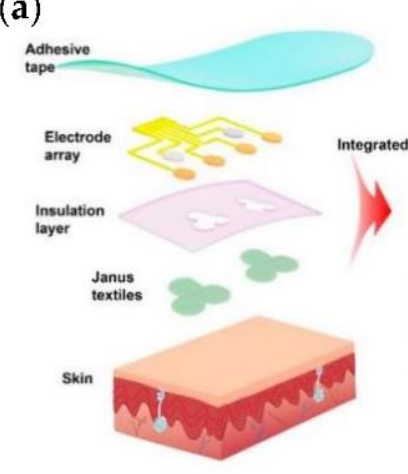

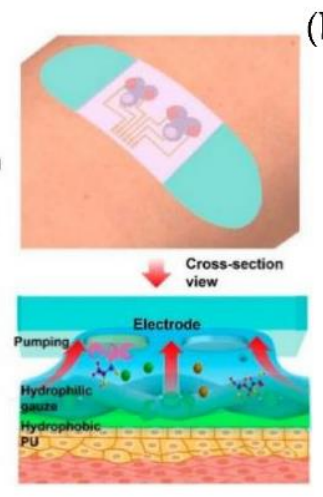

(b)

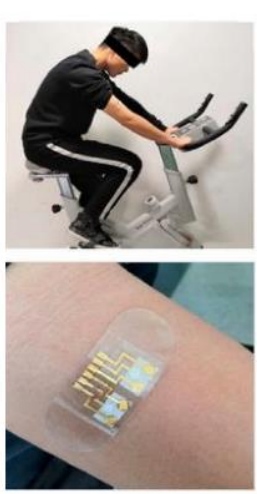

(c)

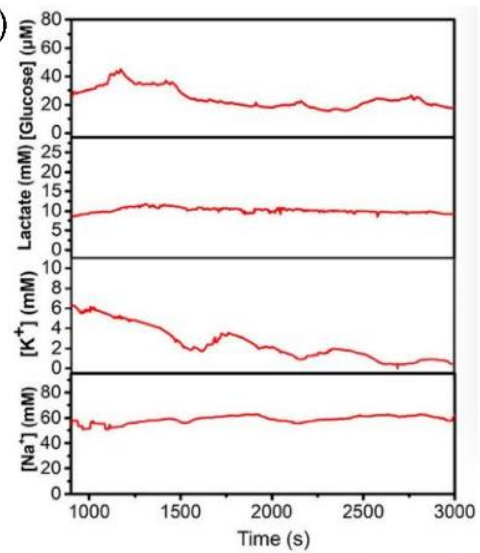

(d)
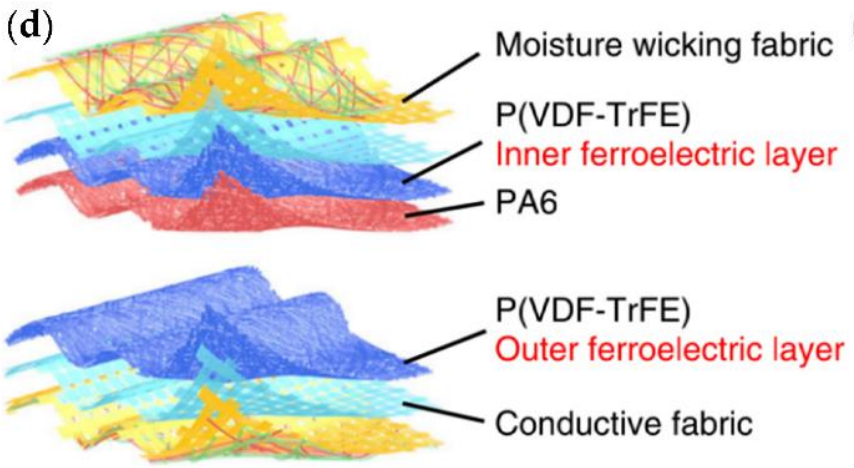

(e)

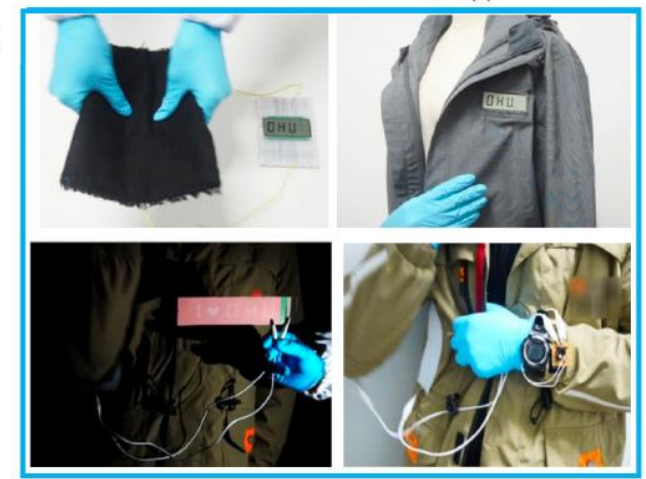

Figure 9. (a) Schematic illustration of the sweat sensor with the Janus textile. (b) Sweat sensor is worn on a volunteer's arm during biking activity. (c) Signal acquisition for each sensor occurred upon adequate sweat sample collection [70] (Copyright 2020, American Chemical Society). (d) Structural diagram of an all-fiber contact-separation mode tribo-ferroelectric synergistic e-textile. (e) Various applications of the e-textile: sewn together with common fabrics, sewn into clothes to power the LCD by shaking the clothes, digital electroluminescent lattices, and digital electronic watch [71] (Copyright 2019, Springer Nature).

In addition, Yang et al. [72] designed the all-fiber tribo-ferroelectric synergistic e-textile, which consisted of two nanofiber nonwovens poly (vinylidene fluoride-trifluoroethylene) (P(VDF-TrFE)) and polyamide 6 (PA6) with opposite tribo-polarity for contact electrification, nickel-copper (Ni-Cu) fabric electrode for charge induction, and the moisture-wicking fabric for directional water transport and rapid evaporation (Figure 9d). The e-textile showed good breathability and moisture permeability as all-fiber layers were porous structures. Besides, the nanofiber network was constructed into a hierarchical structure for realizing the moisture-wicking function of the e-textile. Therefore, the e-textile exhibited a high electrical output of $5.2 \mathrm{~W} \mathrm{~m}^{-2}$ and excellent thermal-moisture comfort. Surprisingly, the e-textile could easily supply power for the LCD, digital electroluminescent lattices, electronic watch, and monitor motion signals (Figure 9e), suggesting a promising high-performance energy harvesting material for electronic clothing.

\subsection{Wound Dressing}

An ideal wound dressing should absorb wound exudates, maintain a moist wound environment, provide gas exchange, as well as act as a barrier against bioliquids close to the wound (Figure 10a) [73]. Conventional hydrophilic wound dressings (e.g., cotton gauze, lint, and bandages) may retain the biological biofluid, leading to wound infection and slower wound healing. DWT fabrics can effectively remove the excessive biofluid and maintain a moist microenvironment to accelerate wound healing and have been widely employed as wound dressing in recent years $[71,73,74]$. 
(a)

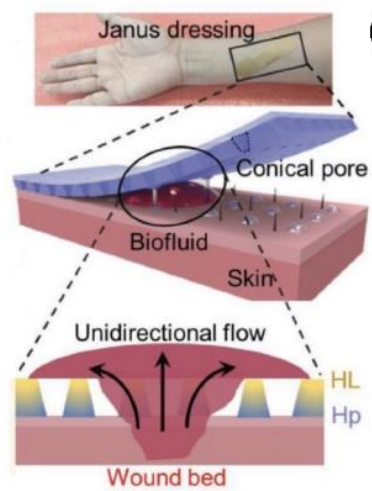

(c)
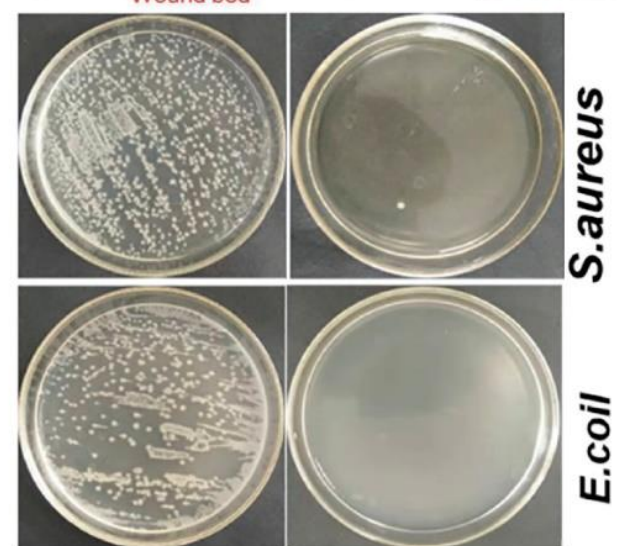

$0 \mathrm{wt} \%$ PHGC $0.06 \mathrm{wt} \%$ PHGC

(b)
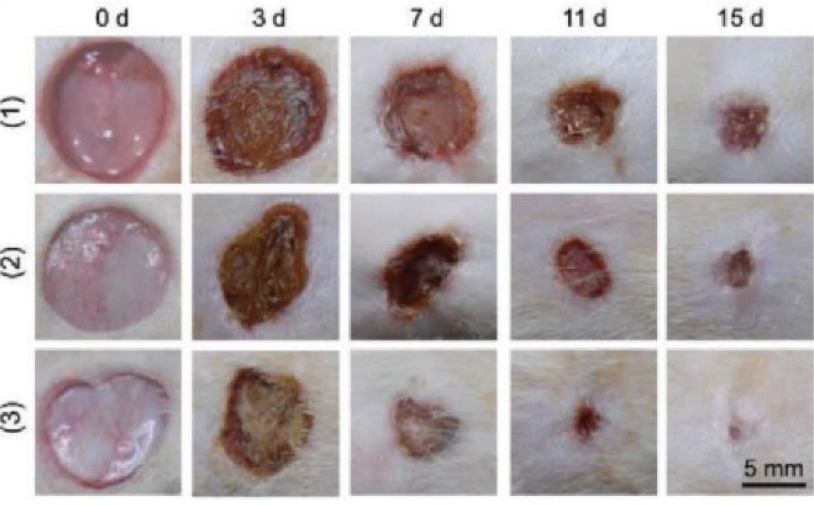

(d)
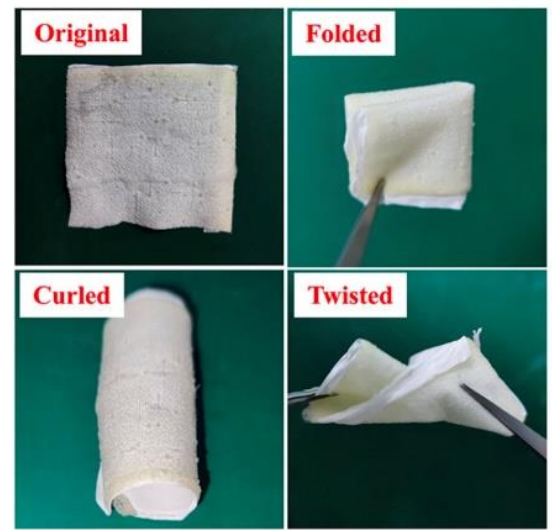

Figure 10. (a) Schematic design of DWT membrane for wound dressing. (b) The images of wounds in different treatment groups: (1) control group; (2) the Janus dressing without antibacterial drug group; and (3) the AM-loaded Janus dressing group [75] (Copyright 2021, Wiley-VCH). (c) Photographs of the antibacterial performance of dressings with no PHGC and $0.6 \mathrm{wt} \%$ PHGC for S. aureus and E. coli [76] (Copyright 2021, Elsevier). (d) Images demonstrating the elasticity and flexibility of the wound dressing [77] (Copyright 2021, American Chemical Society).

Recently, $\mathrm{Xu}$ et al. [75] fabricated a PDMS Janus wound dressing with hydrophobic-to-hydrophilic asymmetric wettability by femtosecond laser and hydrophilicity modification, where the hydrophobic layer was loaded with $0.1 \mathrm{mg}$ amoxicillin (AM) as the antibacterial drug. The asymmetric wettability can drive wound exudates to flow spontaneously from the hydrophobic layer to the hydrophilic layer and prevent liquid penetration in reverse. Furthermore, the composite membrane exhibited a high WVTR of $0.53 \mathrm{~kg} \mathrm{~m}^{-2} \mathrm{~d}^{-1}$, a good waterproof ability, and a sustained release manner for 3 days as well as excellent amoxicillin release of $87.9 \%$. In addition, the Janus dressing with an amoxicillin drug could effectively prevent infection and promote wound healing, which was further supported by animal studies in the murine dorsum. The wound healed nicely and there was no obvious scar in the AM-loaded Janus dressing group compared with the control and Janus dressing group (Figure 10b).

In addition, Qi et al. [76] prepared a three-layered DWT dressing by creating a hydrophobicity-hydrophilicity gradient wettability structure and introducing the antibacterial polyhexamethylene guanidine hydrochloride (PHGC) using electrospinning technology. The three-layered nanofibers showed unidirectional water penetration, high tensile strength of $6.7 \mathrm{MPa}$, good MVTR of $1.36 \mathrm{~kg} \mathrm{~m}^{-2} \mathrm{~d}^{-1}$ and nearly $100 \%$ antibacterial ability against Staphylococcus aureus (S. aureus) and Escherichia coli (E. coli) with $0.06 \mathrm{wt} \%$ PHGC (Figure 10c). However, the present preparation methods often use chemical solvents, which may cause solvent residual, resulting in wound irritation and inflammation. To address this issue, Shao et al. [77] fabricated the solvent-free hydrophobic thermoplastic polyurethane (TPU) microfibers by melt electrospinning, followed by depositing hydrophilic polyamide 6 
(PA6)/poly (ethylene glycol) (PEG) nanofibers on TPU layer by solution electrospinning to obtain the DWT wound dressing. The composite fibers exhibited an excellent unidirectional water transport capacity, a high hydrophobic pressure in the inverse direction $(33.4 \mathrm{~mm})$ as well as good elasticity and flexibility (Figure 10d). Additionally, the directional transfer performance of fibers had no significant changes after 10 water absorption-drying cycles.

\section{Evaluation of DWT Fabrics}

DWT fabrics or textiles are newly developed materials that could be widely applied in functional and technical clothing. Conventional evaluation methods or standards may not meet the demand of testing the DWT fabrics. In the past few years, testing bodies developed some new standards for evaluating DWT or similar types of fabrics or textiles. Two evaluation areas are included: (i) Water/moisture transport (e.g., AATCC Test Method 195: Liquid Moisture Management Properties of Textile Fabrics; AATCC Test Method 197: Vertical Wicking of Textiles; AATCC Test Method 198: Horizontal Wicking of Textiles; and AATCC Test Method 204: Water Vapor Transmission of Textiles) and (ii) Drying behavior (e.g., AATCC Test Method 199: Drying Time of Textiles (Moisture Analyzer Method); AATCC Test Method 200: Drying Rate of Textiles at Their Absorbent Capacity: Air Flow Method; and AATCC Test Method: Drying Rate of Fabrics: Heated Plate Method).

\section{Conclusions and Outlook}

This review summarizes recent research on DWT textile materials. DWT can drive liquid water far away from the skin and keep a comfortable microclimate for the human body. Consequently, DWT materials have been recognized as a robust strategy for achieving efficient moisture management. These have been widely applied in functional clothing, e-textiles and wound dressing. Although much progress has been achieved in the design and fabrication of DWT textile materials, there remain many challenges.

At present, most of the DWT textiles consist of two layers and different layers are made of different fibers. Many fabrication methods are usually complex and cannot accurately control the thickness of each layer; they are limited to the laboratory scale. Therefore, developing some facile, efficient and low-cost methods are urgently needed for industrialization. In addition, many preparation methods need to use fluoro-containing compounds to reach the hydrophobic surface, which is harmful to the human body and environment. Thus, the construction of a rough surface or the use of a non-toxicity reagent are also other methods. Additionally, although a great number of directional water performance tests (e.g., moisture management performance, the water evaporation rate) have been widely carried out in previous studies, these tests are commonly tested under the static state, while human bodies are usually in a dynamic state in practical situations. There is still a lack of a unified evaluation standard, so it is difficult to compare the test results. Therefore, it is necessary to develop many dynamic states test procedures and standardized evaluation methods for DWT textile materials.

Furthermore, there are a few reports about DWT fabrics, especially in hot and high humid environments. It is worth noticing that the water transport performance of DWT fabrics under extreme environments is different from that under normal environments. For example, high-temperature work clothing, summer military physical training clothing, and island residents' wear need a high directional water transport performance. Thus, it is necessary to develop DWT fabrics to satisfy the demand for clothing to be used under high temperature and high humidity environments. With the continuous development and deepening of research, we believe that DWT textile materials will be more widely developed and applied in different fields.

Due to newly development of DWT fabrics and materials, whose properties may not be similar to conventional textiles, for textile and clothing application, new evaluation and characterization methods/standards should be developed to meet the demand. 


\begin{abstract}
Author Contributions: Conceptualization, Y.-Q.X. and C.-W.K.; methodology, Y.-Q.X. and C.-W.K.; validation, C.-W.K.; formal analysis, Y.-Q.X. and C.-W.K.; investigation, Y.-Q.X. and C.-W.K.; resources, C.-W.K.; data curation, Y.-Q.X.; writing-original draft preparation, Y.-Q.X.; writing-review and editing, Y.-Q.X. and C.-W.K.; visualization, Y.-Q.X.; supervision, C.-W.K.; project administration, C.-W.K.; funding acquisition, C.-W.K. All authors have read and agreed to the published version of the manuscript.
\end{abstract}

Funding: This research was funded by The Hong Kong Polytechnic University for the financial support for this work (Account code: ZJM8 and ZDCC).

Institutional Review Board Statement: Not applicable.

Informed Consent Statement: Not applicable.

Data Availability Statement: Not applicable.

Acknowledgments: The authors would like to thank the The Hong Kong Polytechnic University for the financial support for this work (Account code: ZJM8 and ZDCC).

Conflicts of Interest: The authors declare no conflict of interest.

\title{
References
}

1. Dong, Y.; Kong, J.; Phua, S.L.; Zhao, C.; Thomas, N.L.; Lu, X. Tailoring surface hydrophilicity of porous electrospun nanofibers to enhance capillary and push-pull effects for moisture wicking. ACS Appl. Mater. Interfaces 2014, 6, 14087-14095. [CrossRef]

2. Tabor, J.; Chatterjee, K.; Ghosh, T.K. Smart Textile-Based Personal Thermal Comfort Systems: Current Status and Potential Solutions. Adv. Mater. Technol. 2020, 5, 1-40. [CrossRef]

3. Suganthi, T.; Senthilkumar, P. Moisture-management properties of bi-layer knitted fabrics for sportswear. J. Ind. Text. 2017, 47, 1447-1463. [CrossRef]

4. Yang, Y.; Yu, X.; Chen, L.; Zhang, P. Effect of knitting structure and yarn composition on thermal comfort properties of bi-layer knitted fabrics. Text. Res. J. 2020, 91, 3-17. [CrossRef]

5. Prabu, G.T.V.; Chattopadhyay, S.K.; Patil, P.G.; Arputharaj, A.; Mandhyan, P.K.; Prasad, G.K.; Vivekanandan, M.V.; Hadge, G.B.; Nadanathangam, V. Moisture management finish on cotton fabric by electrospraying. Text. Res. J. 2016, 87, 2154-2165. [CrossRef]

6. Liu, J.; Wang, W.; Yu, D.; Zhao, K. Durable Moisture-wicking and Fast-dry Polyester Fabric Prepared by UV-induced Click Reaction. Fibers Polym. 2020, 21, 111-118. [CrossRef]

7. Sathish Babu, B.; Senthil Kumar, P.; Senthil Kumar, M. Effect of yarn type on moisture transfer characteristics of double-face knitted fabrics for active sportswear. J. Ind. Text. 2018, 49, 1078-1099. [CrossRef]

8. Troynikov, O.; Wardiningsih, W. Moisture management properties of wool/polyester and wool/bamboo knitted fabrics for the sportswear base layer. Text. Res. J. 2011, 81, 621-631. [CrossRef]

9. $\quad$ Parker, A.R.; Lawrence, C.R. Water capture by a desert beetle. Nature 2001, 414, 33-34. [CrossRef]

10. Zheng, Y.; Bai, H.; Huang, Z.; Tian, X.; Nie, F.Q.; Zhao, Y.; Zhai, J.; Jiang, L. Directional water collection on wetted spider silk. Nature 2010, 463, 640-643. [CrossRef] [PubMed]

11. Ju, J.; Bai, H.; Zheng, Y.; Zhao, T.; Fang, R.; Jiang, L. A multi-structural and multi-functional integrated fog collection system in cactus. Nat. Commun. 2012, 3, 1247. [CrossRef]

12. Cao, M.; Ju, J.; Li, K.; Dou, S.; Liu, K.; Jiang, L. Facile and Large-Scale Fabrication of a Cactus-Inspired Continuous Fog Collector. Adv. Funct. Mater. 2014, 24, 3235-3240. [CrossRef]

13. Chen, H.; Zhang, P.; Zhang, L.; Liu, H.; Jiang, Y.; Zhang, D.; Han, Z.; Jiang, L. Continuous directional water transport on the peristome surface of Nepenthes alata. Nature 2016, 532, 85-89. [CrossRef]

14. He, X.; Fan, C.; Xu, T.; Zhang, X. Biospired Janus Silk E-Textiles with Wet-Thermal Comfort for Highly Efficient Biofluid Monitoring. Nano Lett. 2021, 21, 8880-8887. [CrossRef] [PubMed]

15. Tang, S.; Pi, H.; Zhang, Y.; Wu, J.; Zhang, X. Novel Janus Fibrous Membranes with Enhanced Directional Water Vapor Transmission. Appl. Sci. 2019, 9, 3302. [CrossRef]

16. Fashandi, H.; Ghomi, A.R. Developing Breathable Double-Layered Fibrous Membranes Equipped with Water Pulling Mechanism Toward Clothing with Enhanced Comfort. Adv. Eng. Mater. 2017, 19, 1600863. [CrossRef]

17. Zhang, H.; Chen, C.; Zhang, H.; Chen, G.; Wang, Y.; Zhao, Y. Janus medical sponge dressings with anisotropic wettability for wound healing. Appl. Mater. Today 2021, 23, 101068. [CrossRef]

18. Li, L.; Mai, Y.; Wang, Y.; Chen, S. Stretchable unidirectional liquid-transporting membrane with antibacterial and biocompatible features based on chitosan derivative and composite nanofibers. Carbohydr. Polym. 2022, 276, 118703. [CrossRef]

19. Li, Y.; Fan, J.; Wang, R.; Shou, W.; Wang, L.; Liu, Y. 3D tree-shaped hierarchical flax fabric for highly efficient solar steam generation. J. Mater. Chem. A 2021, 9, 2248-2258. [CrossRef]

20. Shen, Q.; Jiang, Y.; Guo, S.; Huang, L.; Xie, H.; Li, L. One-step electrospinning membranes with gradual-transition wettability gradient for directional fluid transport. J. Membr. Sci. 2021, 644, 12091. [CrossRef] 
21. Knapczyk Korczak, J.; Stachewicz, U. Biomimicking spider webs for effective fog water harvesting with electrospun polymer fibers. Nanoscale 2021, 13, 16034-16051. [CrossRef] [PubMed]

22. Young, T., III. An essay on the cohesion of fluids. Phil. Trans. R. Soc. 1805, 95, 65-87. [CrossRef]

23. Wenzel, R.N. Resistance of solid surfaces to wetting by water. Ind. Eng. Chem. 1936, 28, 988-994. [CrossRef]

24. Cassie, A.; Baxter, S. Wettability of porous surfaces. Trans. Faraday Soc. 1944, 40, 546-551. [CrossRef]

25. Zhou, H.; Wang, H.; Niu, H.; Zeng, C.; Zhao, Y.; Xu, Z.; Fu, S.; Lin, T. One-Way Water-Transport Cotton Fabrics with Enhanced Cooling Effect. Adv. Mater. Interfaces 2016, 3, 1600283. [CrossRef]

26. Shen, H.; Li, Y.; Yao, W.; Yang, S.; Yang, L.; Pan, F.; Chen, Z.; Yin, X. Solvent-free cellulose nanocrystal fluids for simultaneous enhancement of mechanical properties, thermal conductivity, moisture permeability and antibacterial properties of polylactic acid fibrous membrane. Compos. Part. B Eng. 2021, 222, 109042. [CrossRef]

27. Zhen, Q.; Zhang, H.; Li, H.; Cui, J.-Q.; Cheng, J.; Liu, Y. Wettability Gradient-Structured Bicomponent Polylactic Acid-Viscose Composite Fabrics with Enhanced Asymmetric Water Penetration Characteristics. ACS Appl. Polym. Mater. $2021,3,3354-3362$. [CrossRef]

28. Zhao, Y.; Wang, H.; Zhou, H.; Lin, T. Directional fluid transport in thin porous materials and its functional applications. Small 2017, 13, 1601070. [CrossRef]

29. Yan, W.; Miao, D.; Babar, A.A.; Zhao, J.; Jia, Y.; Ding, B.; Wang, X. Multi-scaled interconnected inter-and intra-fiber porous janus membranes for enhanced directional moisture transport. J. Colloid Interface Sci. 2020, 565, 426-435. [CrossRef]

30. Miao, D.; Wang, X.; Yu, J.; Ding, B. A Biomimetic Transpiration Textile for Highly Efficient Personal Drying and Cooling. Adv. Funct. Mater. 2021, 31, 2008705. [CrossRef]

31. Tian, X.; Li, J.; Wang, X. Anisotropic liquid penetration arising from a cross-sectional wettability gradient. Soft Matter 2012, 8, 2633-2637. [CrossRef]

32. Widodo, M.; Handayani, A.F.; Sumaryadi, G. Tailoring cotton fabric with wettability gradient and anisotropic penetration of liquid by spray coating. J. Text. Inst. 2020, 111, 972-984. [CrossRef]

33. Wei, X.; Zhou, H.; Chen, F.; Wang, H.; Ji, Z.; Lin, T. High-efficiency low-resistance oil-mist coalescence filtration using fibrous filters with thickness-direction asymmetric wettability. Adv. Funct. Mater. 2019, 29, 1806302. [CrossRef]

34. Song, Y.; Chen, X.; Xu, K.; Li, H.; Xu, Y.; Wu, H.; Wu, J.; Huang, C. Green and Scalable Fabrication of Nonwoven Composites Featured with Anisotropic Water Penetration. ACS Sustain. Chem. Eng. 2019, 7, 19679-19685. [CrossRef]

35. Sun, F.; Chen, Z.; Zhu, L.; Du, Z.; Wang, X.; Naebe, M. Directional Trans-Planar and Different In-Plane Water Transfer Properties of Composite Structured Bifacial Fabrics Modified by a Facile Three-Step Plasma Treatment. Coatings 2017, 7, 132. [CrossRef]

36. Airoudj, A.; Bally-Le Gall, F.; Roucoules, V. Textile with Durable Janus Wetting Properties Produced by Plasma Polymerization. J. Phys. Chem. C 2016, 120, 29162-29172. [CrossRef]

37. Lao, L.; Shou, D.; Wu, Y.; Fan, J. "Skin-like” fabric for personal moisture management. Sci. Adv. 2020, 6, eaaz0013. [CrossRef] [PubMed]

38. Pu, Y.; Yang, J.; Russell, S.J.; Ning, X. Cotton nonwovens with unidirectional water-transport properties produced by atmospheric plasma deposition. Cellulose 2021, 28, 4427-4438. [CrossRef]

39. Jaworek, A.; Sobczyk, A.T. Electrospraying route to nanotechnology: An overview. J. Electrost. 2008, 66, 197-219. [CrossRef]

40. Zeng, C.; Wang, H.; Zhou, H.; Lin, T. Directional Water Transport Fabrics with Durable Ultra-High One-Way Transport Capacity. Adv. Mater. Interfaces 2016, 3, 1600036. [CrossRef]

41. Wang, H.; Zhou, H.; Wei, X.; Niu, H.; Lin, T. Highly Permeable, Directional Water Transport Cotton Fabrics. Adv. Mater. Interfaces 2018, 5, 1800815. [CrossRef]

42. Wang, H.; Wang, W.; Wang, H.; Jin, X.; Li, J.; Wang, H.; Zhou, H.; Niu, H.; Lin, T. Pore size effect on one-way water-transport cotton fabrics. Appl. Surf. Sci. 2018, 455, 924-930. [CrossRef]

43. Wang, H.; Wang, W.; Wang, H.; Jin, X.; Li, J.; Zhu, Z. One-Way Water Transport Fabrics Based on Roughness Gradient Structure with No Low Surface Energy Substances. ACS Appl. Mater. Interfaces 2018, 10, 32792-32800. [CrossRef]

44. Malinauskas, M.; Žukauskas, A.; Hasegawa, S.; Hayasaki, Y.; Mizeikis, V.; Buividas, R.; Juodkazis, S. Ultrafast laser processing of materials: From science to industry. Light Sci. Appl. 2016, 5, e16133. [CrossRef]

45. Martínez-Calderon, M.; Martín Palma, R.; Rodríguez, A.; Gómez-Aranzadi, M.; García-Ruiz, J.; Olaizola, S.; Manso-Silván, M. Biomimetic hierarchical micro/nano texturing of TiAlV alloys by femtosecond laser processing for the control of cell adhesion and migration. Phys. Rev. Mater. 2020, 4, 056008. [CrossRef]

46. Ma, Y.; Jiang, L.; Hu, J.; Liu, H.; Wang, S.; Zuo, P.; Ji, P.; Qu, L.; Cui, T. Multifunctional 3D micro-nanostructures fabricated through temporally shaped femtosecond laser processing for preventing thrombosis and bacterial infection. ACS Appl. Mater. Interfaces 2020, 12, 17155-17166. [CrossRef]

47. Li, J.; Zhao, S.; Du, F.; Zhou, Y.; Yu, H. One-step fabrication of superhydrophobic surfaces with different adhesion via laser processing. J. Alloy. Compd. 2018, 739, 489-498. [CrossRef]

48. Starinskiy, S.V.; Rodionov, A.A.; Shukhov, Y.G.; Safonov, A.I.; Maximovskiy, E.A.; Sulyaeva, V.S.; Bulgakov, A.V. Formation of periodic superhydrophilic microstructures by infrared nanosecond laser processing of single-crystal silicon. Appl. Surf. Sci. 2020, 512, 145753. [CrossRef]

49. Chu, D.; Singh, S.C.; Yong, J.; Zhan, Z.; Sun, X.; Duan, J.A.; Guo, C. Superamphiphobic surfaces with controllable adhesion fabricated by femtosecond laser bessel beam on PTFE. Adv. Mater. Interfaces 2019, 6, 1900550. [CrossRef] 
50. Yin, K.; Yang, S.; Dong, X.; Chu, D.; Duan, J.A.; He, J. Ultrafast Achievement of a Superhydrophilic/Hydrophobic Janus Foam by Femtosecond Laser Ablation for Directional Water Transport and Efficient Fog Harvesting. ACS Appl. Mater. Interfaces 2018, 10, 31433-31440. [CrossRef]

51. Ren, F.; Li, G.; Zhang, Z.; Zhang, X.; Fan, H.; Zhou, C.; Wang, Y.; Zhang, Y.; Wang, C.; Mu, K.; et al. A single-layer Janus membrane with dual gradient conical micropore arrays for self-driving fog collection. J. Mater. Chem. A 2017, 5, 18403-18408. [CrossRef]

52. Dai, B.; Li, K.; Shi, L.; Wan, X.; Liu, X.; Zhang, F.; Jiang, L.; Wang, S. Bioinspired Janus Textile with Conical Micropores for Human Body Moisture and Thermal Management. Adv. Mater. 2019, 31, 1904113. [CrossRef] [PubMed]

53. Yang, S.; Zhu, Z.; Wu, Z.; Wu, J.; Yin, K. Femtosecond laser rapid fabrication of Janus sweat-permeable fabric for personal cooling. Appl. Phys. Lett. 2020, 117, 213701. [CrossRef]

54. Xue, J.; Xie, J.; Liu, W.; Xia, Y. Electrospun Nanofibers: New Concepts, Materials, and Applications. Acc. Chem. Res. 2017, 50, 1976-1987. [CrossRef]

55. Wang, X.; Yu, J.; Sun, G.; Ding, B. Electrospun nanofibrous materials: A versatile medium for effective oil/water separation. Mater. Today 2016, 19, 403-414. [CrossRef]

56. Du, M.; Zhao, Y.; Tian, Y.; Li, K.; Jiang, L. Electrospun multiscale structured membrane for efficient water collection and directional transport. Small 2016, 12, 1000-1005. [CrossRef] [PubMed]

57. Huang, G.; Liang, Y.; Wang, J.; Zeng, X.; Li, Z.; Zhang, X. Effect of asymmetric wettability on directional transport of water through Janus fabrics prepared by an electrospinning technique. Mater. Lett. 2019, 246, 76-79. [CrossRef]

58. Babar, A.A.; Zhao, X.; Wang, X.; Yu, J.; Ding, B. One-step fabrication of multi-scaled, inter-connected hierarchical fibrous membranes for directional moisture transport. J. Colloid Interface Sci. 2020, 577, 207-216. [CrossRef] [PubMed]

59. Miao, D.; Huang, Z.; Wang, X.; Yu, J.; Ding, B. Continuous, Spontaneous, and Directional Water Transport in the Trilayered Fibrous Membranes for Functional Moisture Wicking Textiles. Small 2018, 14, 1801527. [CrossRef] [PubMed]

60. Dong, Y.; Kong, J.; Mu, C.; Zhao, C.; Thomas, N.L.; Lu, X. Materials design towards sport textiles with low-friction and moisture-wicking dual functions. Mater. Des. 2015, 88, 82-87. [CrossRef]

61. Liang, Y.; Huang, G.; Zeng, X.; Li, Z.; Zou, J.; Li, X. Effects of hydrophilic layer on directional transport of water through robust tri-layered Janus fabrics prepared by electrospinning. Mater. Lett. 2020, 268, 127583. [CrossRef]

62. Mao, N.; Peng, H.; Quan, Z.; Zhang, H.; Wu, D.; Qin, X.; Wang, R.; Yu, J. Wettability control in tree structure-based 1D fiber assemblies for moisture wicking functionality. ACS Appl. Mater. Interfaces 2019, 11, 44682-44690. [CrossRef]

63. Huang, G.; Jin, Y.; Huo, L.; Yuan, S.; Zhao, R.; Zhao, J.; Li, Z.; Li, Y. An All-Hydrophobic Fluid Diode for Continuous and Reduced-Wastage Water Transport. ACS Appl. Mater. Interfaces 2021, 13, 51708-51717. [CrossRef]

64. Babar, A.A.; Wang, X.; Iqbal, N.; Yu, J.; Ding, B. Tailoring differential moisture transfer performance of nonwoven/polyacrylonitrile-SiO2 nanofiber composite membranes. Adv. Mater. Interfaces 2017, 4, 1700062. [CrossRef]

65. Babar, A.A.; Miao, D.; Ali, N.; Zhao, J.; Wang, X.; Yu, J.; Ding, B. Breathable and Colorful Cellulose Acetate-Based Nanofibrous Membranes for Directional Moisture Transport. ACS Appl. Mater. Interfaces 2018, 10, 22866-22875. [CrossRef] [PubMed]

66. Wang, X.; Huang, Z.; Miao, D.; Zhao, J.; Yu, J.; Ding, B. Biomimetic Fibrous Murray Membranes with Ultrafast Water Transport and Evaporation for Smart Moisture-Wicking Fabrics. ACS Nano 2019, 13, 1060-1070. [CrossRef]

67. Zhang, Y.; Tian, M.; Wang, L.; Zhao, H.; Qu, L. Flexible Janus Textile-Based Electroosmotic Pump for Large-Area Unidirectional Positive Water Transport. Adv. Mater. Interfaces 2020, 7, 1902133. [CrossRef]

68. Wang, H.; Niu, H.; Zhou, H.; Wei, X.; Yang, W.; Lin, T. Multifunctional Directional Water Transport Fabrics with Moisture Sensing Capability. ACS Appl. Mater. Interfaces 2019, 11, 22878-22884. [CrossRef]

69. Gong, W.; Wang, X.; Yang, W.; Zhou, J.; Han, X.; Dickey, M.D.; Su, Y.; Hou, C.; Li, Y.; Zhang, Q.; et al. Wicking-Polarization-Induced Water Cluster Size Effect on Triboelectric Evaporation Textiles. Adv. Mater. 2021, 3, 2007352. [CrossRef] [PubMed]

70. He, X.; Yang, S.; Pei, Q.; Song, Y.; Liu, C.; Xu, T.; Zhang, X. Integrated Smart Janus Textile Bands for Self-Pumping Sweat Sampling and Analysis. ACS Sens. 2020, 5, 1548-1554. [CrossRef] [PubMed]

71. Ye, S.; Jiang, L.; Wu, J.; Su, C.; Huang, C.; Liu, X.; Shao, W. Flexible Amoxicillin-Grafted Bacterial Cellulose Sponges for Wound Dressing: In Vitro and In Vivo Evaluation. ACS Appl. Mater. Interfaces 2018, 10, 5862-5870. [CrossRef] [PubMed]

72. Yang, W.; Gong, W.; Hou, C.; Su, Y.; Guo, Y.; Zhang, W.; Li, Y.; Zhang, Q.; Wang, H. All-fiber tribo-ferroelectric synergistic electronics with high thermal-moisture stability and comfortability. Nat. Commun. 2019, 10, 5541. [CrossRef] [PubMed]

73. Zhang, K.; Jiao, X.; Zhou, L.; Wang, J.; Wang, C.; Qin, Y.; Wen, Y. Nanofibrous composite aerogel with multi-bioactive and fluid gating characteristics for promoting diabetic wound healing. Biomaterials 2021, 276, 121040. [CrossRef] [PubMed]

74. Li, T.-T.; Zhong, Y.; Peng, H.-K.; Ren, H.-T.; Chen, H.; Lin, J.-H.; Lou, C.-W. Multiscale composite nanofiber membranes with asymmetric wetability: Preparation, characterization, and applications in wound dressings. J. Mater. Sci. 2020, 56, 4407-4419. [CrossRef]

75. Xu, B.; Li, A.; Wang, R.; Zhang, J.; Ding, Y.; Pan, D.; Shen, Z. Elastic Janus film for Wound Dressings: Unidirectional Biofluid Transport and Effectively Promoting Wound Healing. Adv. Funct. Mater. 2021, 31, 2105265. [CrossRef]

76. Qi, L.; Ou, K.; Hou, Y.; Yuan, P.; Yu, W.; Li, X.; Wang, B.; He, J.; Cui, S.; Chen, X. Unidirectional water-transport antibacterial trilayered nanofiber-based wound dressings induced by hydrophilic-hydrophobic gradient and self-pumping effects. Mater. Des. 2021, 201, 109461. [CrossRef]

77. Shao, Z.; Chen, J.; Ke, L.J.; Wang, Q.; Wang, X.; Li, W.; Zheng, G. Directional Transportation in a Self-Pumping Dressing Based on a Melt Electrospinning Hydrophobic Mesh. ACS Biomater. Sci. Eng. 2021, 7, 5918-5926. [CrossRef] 